\title{
As organizações não-governamentais de desenvolvimento local e sua prática educativa de adultos: uma análise no norte de Portugal*
}

\author{
Armando Loureiro \\ Universidade de Trás-os-Montes e Alto Douro, Departamento de Educação e Psicologia
}

\section{Introdução}

A educação de adultos assume importância inegável na actualidade mundial, relevo que lhe é atribuído em nível internacional há longa data. Efectivamente, ela tem vindo a converter-se numa preocupação internacional, sobretudo a partir da $2^{\mathrm{a}}$ Grande Guerra Mundial, como comprovam as diferentes conferências efectuadas pela Organização das Nações Unidas para a Educação, a Ciência e a Cultura (UNESCO): Elsinore em 1949, Montreal em 1960, Tóquio em 1972 (Gusmão \& Marques, 1978), Nairóbi em 1976 (UNESCO, 1976), Paris em 1985 (UNESCO, 1985) e Hamburgo em 1997 (UNESCO, 1998).

A sua vivacidade traduz-se numa série de práticas (alfabetização, formação profissional, animação so-

* Este artigo baseia-se numa parte da tese de doutoramento $O$ trabalho, o conhecimento, os saberes e as aprendizagens dos técnicos de educação de adultos numa ONGDL: contribuições etnográficas para uma renovação da sociologia da educação, defendida na Universidade de Trás-os-Montes e Alto Douro/Portugal, em 28 de dezembro de 2006. Foi mantida a ortografia de Portugal. ciocultural etc.), de instituições (sector estatal, sector privado e sector das organizações não lucrativas) e agentes envolvidos na educação de adultos (formadores, educadores de adultos, animadores, gestores da formação, provedores da educação de adultos, engenheiros da formação, animadores de balanço de competências, planificadores e administradores da educação de adultos, técnicos de recursos humanos, avaliadores da formação, orientadores de círculos de estudos, entre outros).

Traduz-se ainda na sua própria institucionalização universitária como disciplina de diversos cursos, como curso em si mesmo, ou como departamento (Universidade Paris 8, Pennsylvania State University, Universidade de Pretória, entre muitas outras), na criação de diversas associações internacionais (European Society for Research on the Education of Adults, American Association for Adult and Continuing Education, European Bureau of Adult Education, International Council of Adult Education e Associação Mediterrânica de Educação de Adultos, entre outras), na existência de revistas cientificas (Studies in Adult Education, Adult Education Quarterly, Perspectives in 
Education etc.), ou na discussão acerca da existência ou não de profissionais da educação de adultos (Jarvis, 1989; Jarvis \& Chadwick, 1991; Merriam \& Brockett, 1997; Sáez \& Palazón, 1994).

Em Portugal assiste-se também, sobretudo nos últimos anos, a um forte dinamismo da educação de adultos. Destacam-se dois movimentos complementares e interdependentes. Por um lado, temos vários tipos de instituições da sociedade civil que têm vindo a assumir-se como espaços de educação não formal (associações, cooperativas, centros de educação e formação etc.) nos quais as práticas de educação de adultos ocupam um lugar importante.

Por outro lado, tem havido forte investimento político nessa área da educação, facto que tem contribuído para o incremento da educação de adultos fora do sistema de ensino formal, a que se fez referência anteriormente, e dentro do próprio sistema. Efectivamente, foram criadas estruturas e desenvolvidos programas que têm vindo a ser postos em prática por diversos tipos de agentes educativos em diversos locais.

Em 1999 foi criada, pelo decreto-lei n. 387/99, a Agência Nacional de Educação e Formação de Adultos (ANEFA), entretanto substituída pela actual Direcção Geral de Formação Vocacional (DGFV), dotando-se, dessa forma, o país de uma estrutura exclusivamente voltada para a educação e formação de adultos. Mais recentemente, em 2006, foi criada, pelo decreto-lei n. 213/06, a Agência Nacional para a Qualificação, que tem como uma das suas missões realizar a coordenação das políticas de educação e formação profissional de jovens e adultos.

Essas estruturas têm vindo a dinamizar e a promover várias iniciativas, como: os cursos Educação e Formação de Adultos (EFA), que são cursos de dupla certificação, escolar até ao $9^{\circ}$ ano e profissional de nível I e II; e o Sistema Nacional de Reconhecimento, Validação e Certificação de Competências, que pelos seus centros permite a certificação escolar ao nível básico ou ao nível secundário por meio de um processo de certificação das competências adquiridas pelos adultos ao longo da sua vida.

Resulta do referido uma nova realidade da educação de adultos em Portugal. O principal objectivo deste artigo é questionar parte dessa realidade. Mais precisamente, partindo da actual conjuntura e da dupla perspectiva teórica que vê a educação de adultos como fonte de desenvolvimento local (Quintana, 1991, 1995) e que vê os processos de desenvolvimento local como espaços privilegiados para a implementação de diversas acções de educação de adultos (Canário, 1999; Rogers, 1995), procura-se realizar um retrato do que se passa a esse nível no norte de Portugal, problematizando tal relação.

Para tal, recorremos a uma parte de um estudo recentemente realizado no qual se fez uma caracterização geral das actividades de educação de adultos efectuadas nas organizações não-governamentais de desenvolvimento local (ONGDL) dos cinco distritos da área geográfica referida: Braga, Bragança, Porto, Viana do Castelo e Vila Real. Numa primeira fase, a recolha dos dados foi feita com base em técnicas documentais, que permitiram identificar as ONGDL com actividades de educação de adultos, assim como determinar seu grau de envolvimento nesse tipo de actividade educativa. Numa fase posterior, a recolha foi feita a partir de entrevistas a uma amostra intencional (os representantes das organizações relativamente às quais foi determinado grau de envolvimento médio e forte em acções de educação de adultos), que permitiram definir o perfil da educação de adultos nas ONGDL. O tratamento da informação fez-se pela análise de conteúdo da informação recolhida.

Tendo em consideração o objectivo definido, começamos por convocar as perspectivas teóricas que nos levam para a identificação dos tipos de educação de adultos e para a discussão da relação entre o desenvolvimento local e a educação de adultos. Apresentamos, de seguida, os principais resultados da pesquisa efectuada, e terminamos com breves reflexões acerca da efectiva contribuição das práticas de educação de adultos para o desenvolvimento local no norte de Portugal.

\section{Modalidades da educação de adultos}

Existem diversas classificações relativamente aos tipos de educação de adultos, pois esse é um 
campo complexo. Canário (1999) refere-se a quatro tipos de práticas educativas: alfabetização, formação profissional contínua, animação sociocultural e os processos articulados de educação de adultos e desenvolvimento local. Knox (1993) refere-se à educação básica de adultos, aos programas culturais, à educação a distância, à educação profissional contínua, ao desenvolvimento rural, à educação superior. Para Quintana (1995), a educação de adultos assume quatro formas: a educação de adultos escolar, a educação de adultos cultural, a educação de adultos profissional e a educação de adultos social. Hinojal (1995) fala também em quatro modalidades: a educação básica de adultos, a formação ocupacional, a formação complementar e a formação para a participação social. Jarvis (1995) refere-se à educação contínua, à educação recorrente e à educação comunitária. Palma e Flecha (1998), por seu turno, apontam três modalidades de educação de adultos: a educação de base, a formação ocupacional e contínua e a formação sociocultural. Por fim, Romans e Viladot (1998) referem-se à existência de três grandes âmbitos na educação de adultos: a formação básica, a formação profissional contínua e a formação para o desenvolvimento comunitário.

Como facilmente se conclui, existem entre essas classificações, e muitas outras que poderiam ser dadas, semelhanças de terminologia e também de conteúdo. Recorrendo a tais classificações e ao contributo de outros autores, apresentamos as modalidades que, em nosso entender, englobam de forma geral as práticas de educação de adultos existentes. A tipologia apresentada deve ser entendida como uma natural redução da realidade existente, realidade essa que muitas vezes se mistura, fazendo com que, por exemplo, uma determinada acção possa ser incluída em mais que um dos tipos apresentados.

Distinguimos a educação compensatória de adultos, a formação profissional, a educação de adultos cultural e a educação de adultos social. Existem ainda práticas mistas de educação de adultos, isto é, actividades educativas que à partida englobam dois ou mais dos tipos apresentados. É o caso, em Portugal, dos cursos EFA, que têm uma componente de educação de base e uma componente de formação profissional.

A primeira modalidade diz respeito àquelas actividades educativas que proporcionam aos adultos o tipo de educação que a escola lhes deveria ter proporcionado mas que por alguma razão não o fez, ou o fez de forma incompleta. Tais ofertas educativas podem ser assumidas pelo sistema formal de ensino ou por outro tipo de instituições.

A esmagadora maioria dessas actividades dirige-se à alfabetização, seja natural (que diz respeito à alfabetização de adultos que nunca passaram pela escola e que não adquiriram a capacidade de ler, escrever e contar noutro qualquer contexto), funcional (procura da capacitação dos adultos que, apesar de terem frequentado a escola, têm falta de saberes básicos de escrita e leitura, ou falta de saber usar esses saberes no seu dia-a-dia), ou migratória (que se refere à alfabetização de estrangeiros que não conseguem comunicar oralmente ou por escrito na língua do país onde estão), e à aquisição da educação considerada básica, que varia de país para país (Canário, 1999; Palma \& Flecha, 1998; Quintana, 1995; Seitter, 1995). No caso português, esse tipo de ofertas educativas tem sido assumida sobretudo pelo ensino recorrente (Canário, 1999), apesar de ser crescente a importância que instâncias não formais de educação vêm assumindo nesse campo, nomeadamente todo um conjunto de organizações não-governamentais, como as associações de desenvolvimento local. Mas esse tipo de modalidade engloba ainda os estudos secundários e até superiores, embora tal suceda mais raramente (Seitter, 1995).

A segunda modalidade que distinguimos, a formação profissional, apresenta vários entendimentos. Assim, há quem fale de formação profissional contínua quando se refere às actividades dirigidas a trabalhadores, há quem use a mesma designação englobando todos os indivíduos que se encontram em idade activa, quer estejam empregados ou não. Há também, e para dar apenas mais um exemplo, quem distinga a formação profissional contínua, destinada a trabalhadores, da formação ocupacional, destinada a desempregados. 
Para nós, a formação profissional diz respeito ao conjunto de actividades formativas cujos públicos e conteúdos são definidos tendo por referência as actividades de trabalho (Dubar \& Gadéa, 2001). Assim, incluem-se nessa modalidade as formações iniciais, as de reciclagem e de reconversão profissional.

Distinguimos, seguindo de perto Palma e Flecha (1998), as formações que se dirigem a desempregados (quer a pessoas que nunca tiveram um emprego, quer às que já o tiveram mas que, no momento da formação, se encontram na situação de desemprego), que designamos por formação ocupacional, das formações que se dirigem a trabalhadores, que designamos por formação profissional contínua. Aqueles autores falam apenas de formação contínua quando se referem às actividades dirigidas a adultos com trabalho; no entanto, pensamos que a designação que adoptamos, formação profissional contínua, que aliás é usada também por outros autores (Canário, 1999, entre outros), é mais precisa, pois, como afirmam Dubar e Gadéa (2001, p. 144), num sentido amplo qualquer formação destinada a pessoas pertencentes à população activa, empregadas ou não, "diz respeito à formação contínua".

Por educação de adultos cultural, o terceiro tipo distinguido, entendemos o conjunto de actividades que têm como objectivo desenvolver e complementar a educação dos adultos. São aquelas acções que Palma e Flecha (1998) designam por formação sociocultural, que engloba o conjunto de cursos cujos conteúdo e objectivos não se dirigem a uma formação profissional ou básica. É o tipo de educação que inclui as ofertas educativas destinadas ao desenvolvimento e complemento por parte dos adultos dos seus conhecimentos históricos, psicológicos, políticos, sociais, entre outros; suas habilidades artísticas, físicas, fotográficas, musicais, culinárias, entre outras; bem como à aquisição de novas capacidades linguísticas (idiomas), informáticas, tecnológicas, entre outras (Hinojal, 1995; Quintana, 1995).

Por fim, temos a educação de adultos social, também designada como educação de adultos para o desenvolvimento comunitário ou local, participação comunitária, ou como formação para a participação social. Os seus principais objectivos são a educação da personalidade, da mentalidade, das atitudes dos adultos, são a sua consciencialização, a sua elaboração do conhecimento do meio, de forma que possam transformá-lo, são o desenvolvimento da sua capacidade para participar na vida social, cultural, política e económica. Isso não quer dizer que as actividades de educação básica ou profissional não possam estar presentes nesses programas de educação social de adultos, bem pelo contrário (Allegrini, 2000; Canário, 1999; Rogers, 1995; Romans \& Viladot, 1998). De forma geral, pode-se dizer que essa educação de adultos procura realizar "uma consciencialização das colectividades, capacitando-as para que tomem partido nos seus próprios problemas e saibam intervir nas decisões que lhes concernem"; enfim, procura "promover o desenvolvimento comunitário" (Quintana, 1986, p. 9-10).

Em rigor, essa última modalidade apresentada não é bem um tipo de educação de adultos, mas sim um processo mais amplo que contempla - ou pode contemplar - diversos tipos de educação de adultos. Como refere Canário (1999, p. 15), “os processos de desenvolvimento local participativo se instituem como momentos de síntese dos diferentes pólos que definem a educação de adultos (animação, alfabetização, formação profissional)".

Devemos esclarecer também que, apesar de considerarmos que a educação de adultos é um elemento essencial do desenvolvimento local, não pensamos que este se reduz àquela dimensão. Concebemos o desenvolvimento local como um processo educativo de toda a comunidade e não apenas dos adultos, embora consideremos que estes são os que têm o protagonismo nesse processo, pois são essencialmente eles que assumem "as acções de desenvolvimento, enquanto principais desencadeadores e executores do planificado pela comunidade" (Allegrini, 2000, p. 23). Por isso, interessa-nos particularmente essa dimensão do processo, daí resultando, da nossa parte, uma análise das interacções entre a educação de adultos e o desenvolvimento local. 


\section{A educação de adultos no contexto do desenvolvimento local}

A este nível, do espaço local, a questão encontra-se estruturada do ponto de vista teórico, de maneira geral, de duas formas complementares: por um lado, vê-se a educação de adultos como um elemento muito importante de desenvolvimento local; e encaram-se, por outro, os processos de desenvolvimento local (ou parte deles) como espaços privilegiados de educação de adultos, como processos que em si são educativos.

Quintana $(1991,1995)$ afirma que a educação de adultos, segundo a actual tendência mundial, é apontada como um instrumento de desenvolvimento das comunidades locais e de capacitação dos indivíduos para promoverem-se em comunidade, e refere uma série de casos e programas (no Canadá, no Egipto, o Projecto n. 9 do Conselho de Cooperação Cultural da Europa - Educação de Adultos e Desenvolvimento Comunitário, a Iniciativa Leader ${ }^{1}$ ) para o mostrar.

Efectivamente, desde há décadas que a educação de adultos vem sendo apontada como um factor de desenvolvimento local, nomeadamente do território rural (Ferrando, 1996; Lovett, 1982; Mosele \& Caspar, 2000; UNESCO, 1982; Werthein, 1983). Por vezes, essa potencialidade é realçada a partir de um dos tipos de educação de adultos, como a alfabetização ou educação básica (Ferrando, 1996; Ramos, 2001), ou, e sobretudo, a formação profissional (Cristóvão, 2000; Jover, 1999; Pedroso, 1998; Soares, 2001).

Em Portugal, têm sido vários os autores que se têm referido a essa potencialidade da educação de adultos. Por exemplo, Silva (1990, p. 70) identificou uma série de actividades que designou por "iniciativas para o desenvolvimento [...] que se dirigem estrategicamente para a identificação de problemas colectivos locais e para a escolha e realização de soluções por via da mobilização prioritária de recursos e vontades locais".

Muitas dessas iniciativas assentam na designada investigação participativa, ou investigação-acção,

${ }^{1}$ O Leader é um programa de desenvolvimento rural financiado pelos Fundos Estruturais da União Europeia. que são indicadas como metodologias ou estratégias de educação de adultos que visam precisamente o desenvolvimento local (Erasmie, 1990; Melo, 1994; Quintana, 1986, 1991, 1995). Essa metodologia tem por base ajudar os adultos a saber usar o conhecimento produzido nos sistemas dominantes de produção do conhecimento e contribuir para que os adultos exteriorizem e construam seu próprio conhecimento como forma de resolver seus próprios problemas e, dessa forma, conseguir melhorar suas condições de vida.

Quanto à questão de encarar o desenvolvimento local como espaço de práticas educativas de adultos, como processo de educação de adultos, ela tem sido problematizada de diversas formas. Canário (1999) salienta o conjunto de articulações que se estabelecem entre a educação de adultos e o desenvolvimento a uma escala local, em que ocorre uma forte valorização da participação dos interessados, e entende que esses mecanismos de desenvolvimento local se constituem como um processo colectivo de aprendizagem. $\mathrm{O}$ autor defende que o estudo desse tipo de desenvolvimento é relevante, porque permite reflectir sobre os conceitos e as práticas de educação de adultos por dois motivos: por um lado, porque possibilita questionar a forma escolar que continua a ser dominante na educação de adultos; por outro, porque esses processos de desenvolvimento local são momentos de confluência das diferentes práticas existentes (animação, alfabetização, formação profissional), o que torna possível contrariar determinadas visões estanques do fenómeno. Friedman (1996), ao referir-se ao que designa por desenvolvimento alternativo, assente na ideia de empowerment, também realça o espaço comunitário como um espaço de aprendizagem social.

Têm sido vários os autores portugueses (Canário, 1999; Rothes, 1998; Silva, 1990) a alertar para o aparecimento, no nosso país, de um conjunto vasto de projectos de desenvolvimento local que, com designações diversas (animação ou educação para o desenvolvimento, educação comunitária ou "extra-escolar" de adultos etc.), se apresentam como espaços educativos e se constituem em "contextos excelentes de realização das diferentes modalidades do trabalho educativo com 
adultos" (Rothes, 1998, p. 46). Muitas dessas iniciativas têm surgido fora ou nas franjas da rede pública, precisamente junto de estruturas associativas ligadas ao desenvolvimento local, que têm demonstrado potencialidade para a educação de adultos (Lima, 1994; Norbeck, 1983; Rothes, 1998).

Da V Conferência Internacional sobre Educação de Adultos da UNESCO resultou uma série de recomendações que ajudam a justificar a pertinência desses espaços como unidades de análise, precisamente porque nos remetem para eles como contextos importantes de realização de educação de adultos. Por exemplo, afirma-se que é necessário "reconhecer e financiar adequadamente o crescente papel [...] dos grupos locais na criação de oportunidades educativas" (UNESCO, 1998, p. 11).

Efectivamente, um olhar sobre as actividades de muitas dessas estruturas locais de desenvolvimento demonstra a importância que as acções de educação de adultos, sobretudo as de formação profissional, assumem no conjunto das actividades que põem em prática. Na descrição que Monteiro (2002, p. 262) realiza das actividades concretizadas por esse tipo de instituições em Portugal, é evidente esse facto, pois as "actividades mais comuns" dessas organizações são precisamente as que dizem respeito às actividades de ensino e/ou formação profissional (48\%). Outros dados vão também no sentido do relevo das actividades de educação de adultos nessas organizações locais, nomeadamente em associações (ANIMAR, 1998; Candeias, 2002; Guimarães \& Sancho, 2001).

Assim, a associação entre desenvolvimento local e educação de adultos é um facto. Mas, e apesar de já termos dado algumas indicações nesse sentido, ainda não concretizamos a ideia de que aquele processo é, ou pode ser, em si um processo educativo de adultos. A educação de adultos aparece associada ao desenvolvimento local de diversas formas: há programas de desenvolvimento local que põem em prática acções educativas de adultos de forma esporádica, não muito planeada e não integrada; há programas de desenvolvimento local que tiveram origem em programas de educação de adultos; e há programas de desenvolvimento local nos quais a educação de adultos aparece, desde a sua origem, como parte integrante do próprio programa de desenvolvimento local, assumindo, nesses casos, os adultos um papel determinante no desenrolar de todo o processo de desenvolvimento.

É essa última vertente que pensamos que a associação entre o desenvolvimento local e a educação de adultos deve tomar. Isto é, defendemos, na linha de diversos autores (Allegrini, 2000; Canário, 1999; Melo, 1988; Rogers, 1995), que o desenvolvimento local deve integrar, desde início, a vertente educativa de forma articulada.

Vejamos então como o desenvolvimento local pode ser entendido como um processo educativo de adultos. $\mathrm{O}$ desenvolvimento local parte da situação existente no local, ou seja, das necessidades, dos problemas reais das populações e dos seus recursos e oportunidades de desenvolvimento. Assim, o primeiro passo consiste em identificar, com a participação activa da população, as preocupações, os problemas, os interesses dessa mesma população. Trata-se de um momento de descoberta e problematização da situação existente, que remete para a experiência passada e conhecimento dos autóctones, para a percepção que se tem dos recursos e também para as aspirações existentes. É o momento de consciencialização, ou seja, de construção de uma visão crítica sobre a realidade presente, de produção de conhecimento.

Esse processo tem um valor formativo enorme, pois por ele as pessoas aprendem a conhecer-se melhor, a conhecer a realidade de outra forma e a poder intervir no seu meio com mais capacidade transformativa. Esse processo exige muita informação, diálogo, debate, comunicação, cooperação. Isso não quer dizer que a consciencialização consista numa série de conferências, por exemplo, sobre os problemas; também não consiste na simples informação e também não deve assentar na ideia errada de que os autóctones não possuem qualquer tipo de consciência sobre a realidade que é sua. A consciencialização é um processo de troca, de partilha de percepções entre agentes externos e a própria população. É, dessa forma, um processo de aprendizagem mútua, de construção 
colectiva do conhecimento, no qual participam agentes externos (técnicos de desenvolvimento local e outros) e os interessados nesse processo, passando estes de simples destinatários a participantes do seu próprio desenvolvimento.

Assim entendida, a consciencialização é, então, um processo de educação em que os profissionais assumem um papel de educadores/educandos, da mesma forma que a população assume um papel de educandos/educadores (Canário, 1999; Freire, 1971, 1975, 1977; Melo, 1988; Quintana, 1991; Ramos, 2001; Rogers, 1995).

Esse tipo de abordagem está logicamente no pólo oposto àquele que assenta a sua visão e intervenção numa filosofia burocrática e tecnocrática. Ele exige dos trabalhadores do desenvolvimento local uma aprendizagem que passa, por exemplo, pelo questionamento das suas próprias ideias e práticas, pelo desenvolvimento da capacidade de saber escutar, observar, perceber, formular questões, saber ter abertura para experimentar (Rogers, 1995). Na nossa perspectiva, é com base nesse processo de problematização, de consciencialização mútua que os programas de educação e formação de adultos devem ser construídos nos processos de desenvolvimento local.

Assim, a educação de adultos no contexto do desenvolvimento local deve partir dos recursos locais - sobretudo dos humanos e das suas necessidades, saberes e experiências -, numa perspectiva de valorização desses mesmos recursos. Deve, dessa forma, proporcionar uma forte ligação das aprendizagens teóricas às suas aplicações no contexto de actuação dos indivíduos, sem que isso queira dizer que tal formação se limite a esse contexto. Deve basear-se na troca de saberes e experiências entre os vários intervenientes no processo (educadores, educandos, técnicos, outros); deve, portanto, ser um processo baseado em métodos interactivos, participativos, cooperativos, um processo relacional e dialógico. Deve ser, naturalmente e tendo em conta o dito antes, uma educação descentralizada. Deve, evidentemente, proporcionar a transformação dos formandos, por meio de processos que combinem a componente técnica, instrumental da educação, com a componente da cidadania, das atitudes. Deve, enfim, ser um processo de capacitação dos adultos para a análise crítica, a compreensão e a transformação do meio (Allegrini, 2000; Cristóvão, 2000; Muge, 1988; Quintana, 1991; Ramos, 2001; Sarramona, 1998). Consideramos esses os princípios básicos dos processos de educação e formação de adultos integrados nos programas de desenvolvimento local.

Neles estão contidos já, pelo menos de forma implícita, aquilo que alguns autores consideram ser os conteúdos da educação de adultos nesses contextos de desenvolvimento (Allegrini, 2000; Cristóvão, 2000; Melo, 1988; Rogers, 1995). Os conhecimentos, ou seja, o conjunto de dados e informações acerca de determinado assunto, e as capacidades ou habilidades para desempenhar com eficácia determinada tarefa são dois dos mais importantes conteúdos do processo educativo. Mas a aquisição de novos conhecimentos e capacidades tem de basear-se na compreensão para que os adultos possam saber fazer uso dos conhecimentos e das capacidades que aprenderam, ou seja, para que os saibam mobilizar em contextos que não os da aprendizagem em si, mas em contextos de uso. No entanto, tal pode não ser suficiente para que haja alteração da acção dos adultos e transformação do meio; por isso e para isso é essencial outro aspecto: o desenvolvimento de atitudes positivas por parte dos adultos, como seja a autoestima, o autoconhecimento, a motivação, a confiança, a autonomia, a capacidade de liderança, de iniciativa, de criatividade, entre outras. Assim, pode-se dizer que os conteúdos considerados são os conhecimentos, as capacidades, a compreensão e as atitudes.

Todos esses aspectos concretizam-se, basicamente, em três tipos de acções educativas: informação, formação e animação (Allegrini, 2000), nos quais o técnico de desenvolvimento local tem um papel essencial. Ele "deve aceitar [...] o encargo de revelar e explorar todas as potencialidades educativas" das mais diversas situações quotidianas, bem como "o de definir momentos privilegiados de trabalho formativo mais estruturado e de os coordenar" (Melo, 1988, p. 61). Ele deve ajudar os adultos a assumir sua informação, sua formação e sua animação. 
A posse de informação é essencial para a acção, para a reflexão e para a transformação do meio. Dessa forma, os adultos devem estar na posse de dados concretos para que possam participar no processo de desenvolvimento. Mas os técnicos de desenvolvimento, para além de fornecerem informação, devem também ser capazes de tornar os adultos capazes de, por si, saber seleccionar, procurar, adquirir e saber realizar um tratamento e uso adequado da informação que lhes interessa. Isso passa pelo desenvolvimento das capacidades de compreensão da leitura, da capacidade de observação e de escuta (Allegrini, 2000).

A formação no desenvolvimento local assume duas modalidades, ou, se preferirmos, dirige-se a dois tipos de intervenientes: à população e aos técnicos de desenvolvimento local (idem). No que toca à população, ela assume diversas formas, como seja a formação geral, a formação profissional, a formação para a participação social etc. Relativamente aos técnicos, a autora defende que eles devem ter uma preparação demorada e específica que contemple conhecimentos em desenvolvimento local, em ciências sociais e em educação de adultos. Para além disso, defende ainda que devem saber trabalhar em equipa.

Esse aspecto da formação dos técnicos e também de dirigentes e formadores é uma preocupação antiga dos próprios agentes. Norbeck (1983) fazia referência à necessidade de formação sentida pelos próprios dirigentes das associações populares em Portugal. Lima (1986) fazia o mesmo género de alerta para essa preocupação por parte dos representantes das associações de desenvolvimento do Alto Minho. Praticamente 20 anos depois, o representante duma organização local de desenvolvimento estabelece como um dos objectivos prioritários para o futuro das associações de desenvolvimento local em Portugal a formação e a qualificação dos seus dirigentes, técnicos e animadores (Brás, 2001). O próprio programa Leader construiu um guia de boas práticas de formação para tentar responder às necessidades dos técnicos que, em nível local, põem em prática o programa e que não têm formação para tratar das questões da educação e formação de adultos no contexto do desenvolvimento local:

$$
\text { O presente guia preconiza uma abordagem da definição }
$$
e da realização da formação centrada nas necessidades do processo de desenvolvimento. Pode ser utilizado logo que surja a questão de saber como conceber e realizar tais acções de formação. Este guia dá assim resposta a uma preocupação expressa muitas vezes pelos grupos Leader - sabemos que a formação é importante, nunca conseguiremos atingir um desenvolvimento local verdadeiramente eficaz e sustentável sem valorizar os recursos humanos do território. Mas [...] qual deverá ser o nosso papel neste domínio enquanto grupo Leader? (Mosele \& Caspar, 2000, p. 15)

Assim, pensamos poder concluir que a formação no desenvolvimento local é uma questão múltipla e que diz respeito, de diversas formas, aos agentes profissionais e às populações locais.

Por fim, a animação procura motivar, tornar criativos e fazer participar os adultos em particular e a população em geral no seu próprio desenvolvimento. É uma metodologia educativa facilitadora da informação e da formação das comunidades (Allegrini, 2000).

Preconizar essa modalidade de educação de adultos, que designámos antes por educação de adultos social, é, de forma sintética, partir da situação existencial do adulto e do meio que o rodeia, realizar um processo conjunto de consciencialização, portanto de construção social do conhecimento, e a partir daí estabelecer um programa de educação e formação que vise tornar capaz a reflexão, a acção e a transformação do adulto e do seu meio por ele próprio. É ainda deixar claro que, nessa forma de conceber a educação de adultos, todos se educam.

\section{A educação de adultos nas ONGDL no norte de Portugal}

Nesta secção apresentamos os principais resultados da investigação realizada. Ela divide-se em duas partes: na primeira mostram-se os passos dados para definirmos o grau de envolvimento das ONGDL dos cinco distritos em acções de educação de adultos; na segunda define-se o perfil desse tipo de educação com base na realização de entrevistas feitas a técni- 
cos das instituições mais envolvidas em acções de educação de adultos. Terminamos esta análise dando conta das principais dificuldades identificadas pelos entrevistados quanto à implementação e à realização da educação de adultos.

\section{Grau de envolvimento das ONGDL na educação de adultos ${ }^{2}$}

Identificámos perto de 6 mil organizações de vários tipos (associações, agências, cooperativas, entre outras) nos cinco distritos. Dessas, 107 eram ONGDL, a maior parte das quais não tinha envolvimento visível em educação de adultos: apenas 44 delas tinham actividades desse género. Devemos esclarecer que consideramos apenas os contextos organizativos onde o acto educativo apareceu de forma perfeitamente intencional e diferenciado.

O grau de envolvimento dessas ONGDL em actividades de educação de adultos é diferente. Para o determinarmos, usámos três dimensões de análise: a participação em diversas acções de educação de adultos; o reconhecimento da qualidade da educação de adultos praticada - ONGDLs premiadas por acções de educação de adultos (considerámos as que foram premiadas no Concurso Nacional S@ ber +, da ANE$\mathrm{FA}^{3}$ ); e o reconhecimento de competência institucional

2 Os dados referentes a esta parte foram recolhidos em diversas fontes: governos civis dos cinco distritos do norte de Portugal; centros das áreas educativas dos cinco distritos; Guia das Iniciativas de Desenvolvimento Local (ANIMAR, 1998); http:// www.ppdriqade.pt/; http://www.equal.mts.gov.pt/; documentos do Leader I e II; documentos da ANEFA; Unidade de Educação de Adultos da Universidade de Braga; http://www.inofor.pt/; documentos da Associação Portuguesa para o Desenvolvimento Local (ANIMAR) (lista de associados); documentos da Federação Portuguesa das Associações de Desenvolvimento Local Minha Terra (lista de associados).

3 Trata-se de um concurso que premiava acções de curta duração que visavam à melhoria das qualificações escolares e profissionais da população adulta. externa para terem educação de adultos (considerámos as entidades que foram acreditadas pela ANEFA para serem promotoras de Centros de Reconhecimento, Validação e Certificação de Competências - CRVCC -, as que foram designadas pela ANEFA para serem entidades promotoras de cursos EFA em observação, por região em 2000/2001, e, por fim, as entidades acreditadas pelo Instituto para a Inovação na Formação para realizar formação profissional).

Para verificarmos o nível de envolvimento de cada ONGDL em educação de adultos tendo em conta as três dimensões em conjunto, construímos uma escala de três níveis de envolvimento: forte, para aquelas ONGDL que tiveram resultado igual ou superior a 1 ; médio, para as que tiveram resultado superior a 0 e inferior a 1; e fraco, para as que tiveram resultado inferior a 0 . Os resultados obtidos mostram que nove ONGDLs têm forte envolvimento em educação de adultos, 17 têm envolvimento médio e 18 têm fraco envolvimento. O objectivo da determinação do grau de envolvimento das ONGDLs em educação de adultos foi a realização de uma selecção das ONGDLs a inquirir. A escolha recaiu sobre aquelas que tinham grau de envolvimento médio ou forte (26 ONGDLs); foi com base nelas que definimos o perfil da educação de adultos praticado nesse tipo de organização e identificámos as principais dificuldades na implementação desse tipo de actividades.

\section{O perfil da educação de adultos nas ONGDL}

Nesta parte tenta-se definir o perfil da educação de adultos praticada nesse tipo de organizações a partir da resposta a perguntas como as que se seguem: o que é que tem sido feito? Assente em que estruturas? Com que objectivos? Como tem sido feito? Essas questões correspondem a quatro dimensões de análise: produtos; estrutura/organização; estratégias/políticas; processo/forma. De seguida, dá-se resposta às questões enunciadas, começando por aquela que diz respeito à estrutura/organização que essa actividade assume nessas instituições.

A maior parte das instituições tinha pessoas que 
se dedicavam especificamente à educação de adultos (20). No entanto, somente em oito casos ela se encontrava enquadrada por algum tipo de estrutura específica. $\mathrm{O}$ número de pessoas envolvidas em actividades de educação de adultos por instituição era variável, em mais de metade dos casos essas actividades eram assumidas por até três pessoas.

Tais pessoas desenvolviam vários tipos de acções, que agrupámos tentando dar uma certa uniformidade aos dados recolhidos. Assim, temos: o diagnóstico, a concepção e o planeamento dos projectos, que contemplam todo um trabalho de caracterização e organização referente aos cursos a realizar e que culminam normalmente na realização de candidaturas aos programas que financiem tais cursos; depois há a fase de implementação do que foi planeado, que exige todo um trabalho de divulgação do que se vai fazer, de selecção de formandos e formadores, e outro tipo de actividades que permitam pôr no terreno o que foi planeado; segue-se a execução propriamente dita dos projectos, que engloba sua coordenação técnicopedagógica, administrativa e financeira, o acompanhamento de formandos e de formadores; e, finalmente, a avaliação dos projectos.

Quanto aos produtos/tipos de educação de adultos praticados por essas instituições foram identificados os seguintes: formação profissional, que se divide em formação ocupacional (formação profissional para não activos - jovens adultos à procura do $1^{\circ}$ emprego e desempregados) e em formação profissional contínua (formação profissional destinada a activos, ou seja, a pessoas que desenvolvem a sua actividade na área em que a formação é dada); educação compensatória de adultos, que assume as formas da alfabetização e da educação de base (aqui considerámos os cursos ao nível do $1^{\circ}$ e $2^{\circ}$ ciclo do ensino recorrente; a actividade desenvolvida pelos CRVCC, que reconhece, valida e pode certificar conhecimentos adquiridos pelas pessoas, escolares ou não, ao nível do $1^{\circ}, 2^{\circ}$ e $3^{\circ}$ ciclos do ensino básico; e ainda cursos de alfabetização não certificados da educação extra-escolar); a educação de adultos cultural, também designada por animação sociocultural (exposições, ateliês que promovem discussões temáticas, disponibilização de informação vária à comunidade, palestras informativas, entre outras actividades intencionalmente postas ao serviço dos adultos); actividades mistas de educação de adultos, ou seja, actividades de educação de base e de formação profissional (nesse caso trata-se da junção numa actividade de dois tipos de educação, a escolar e a profissional, como é o caso dos cursos EFA, que dão certificação escolar e dão também certificação profissional, como já foi dito); considerámos ainda a categoria outros (na qual enquadrámos uma série de actividades que se afastam dos tipos considerados anteriormente, como por exemplo o apoio pedagógico a pessoas que se propõem a exame do ensino recorrente).

As acções com maior significado nessas instituições têm sido as de formação ocupacional, pois muitas delas (18) a tinham na altura da recolha dos dados. A formação profissional contínua, as actividades mistas e a educação compensatória também têm assumido relevo.

A que tipo de objectivos procuram responder as práticas de educação de adultos nessas instituições? Que tipo de estratégia existia relativamente a essa matéria? São instituições com projectos definidos de educação de adultos?

Comecemos pelos objectivos/finalidades a que tais acções têm procurado responder. $\mathrm{O}$ objectivo mais referido foi a inserção no mercado de trabalho das pessoas a quem se destinavam as acções (11 entrevistados). O predomínio desse objectivo é natural, tendo em conta que, em muitas dessas instituições, têm existido sobretudo acções de formação profissional, como vimos. Portanto, está muito presente a lógica do mercado de trabalho, associada a uma lógica do acudir a necessidades dos destinatários por meio da formação.

Muito menos presente esteve o discurso do desenvolvimento local. Na verdade, apenas seis entrevistados se referiram à educação de adultos como um meio para o atingir, e ainda assim com lógicas muito diferentes, o que é necessário assinalar. $\mathrm{Na}$ verdade, dois dos entrevistados reportaram-se a esse 
aspecto duma forma que pouco terá a ver com as lógicas mais próximas do desenvolvimento local tal qual o entendemos. A forma como consideram que a educação de adultos contribui para o desenvolvimento local é baseada numa lógica do imediatismo, do curto prazo, que efectivamente não produzirá qualquer desenvolvimento local a prazo, nem sequer a curto, mas sim contribuirá para a reprodução de dependências várias, a mais grave das quais é a daqueles a quem se destinam tais práticas. E dizemos isso porque para esses entrevistados a promoção do desenvolvimento local proporcionado por essas actividades resume-se à distribuição do dinheiro vindo de tais acções por formandos, formadores e técnicos.

A escassa referência à educação de adultos como factor de desenvolvimento local, ou, se quisermos, como parte do próprio desenvolvimento local, é de estranhar. Quererá isso dizer que ela não aparece de forma integrada no contexto do desenvolvimento local?

Houve quem tivesse assumido que os objectivos das actividades desenvolvidas são totalmente definidos pelos programas a que se candidatam, que são enquadrados pela política da União Europeia. Esse aspecto da existência desses objectivos previamente e centralmente definidos, nos quais têm que se enquadrar as candidaturas, sob pena de não serem aprovadas, pode levar à existência de um problema: o desajuste entre tais objectivos e as realidades onde eles se aplicam. É que os públicos desfavorecidos, as regiões menos desenvolvidas de países como a França ou a Alemanha, não são iguais aos públicos portugueses nem às suas regiões, mas os objectivos desses programas e os demais critérios são, muitas vezes, os mesmos, estando-se portanto, nesses casos, a deliberar medidas e objectivos uniformes para realidades muito diversas.

Foi notório também o predomínio da definição dos objectivos a atingir com as actividades com base no critério das necessidades. Tal facto merece dois comentários. Por um lado, esse tipo de levantamento é pertinente desde que se faça com os interessados, isto é, com a sua participação na identificação dos problemas e na procura de soluções. Por outro, a par desse discurso das necessidades, seria de esperar outro centrado na valorização dos recursos existentes, na valorização daquilo que as pessoas já sabem. Porque a maneira de encarar o desenvolvimento local assenta em princípios como os da participação e da endogeneidade e porque as concepções mais recentes da educação de adultos assentam na valorização e no reconhecimento de saberes, das competências adquiridas pelas pessoas ao longo da vida. Ora, seria de esperar que as instituições de que estamos a falar materializassem esse discurso.

Portanto, há aqui um desfasamento entre aquilo que é preconizado, defendido em termos teóricos e em termos de modelos, e o discurso daqueles que põem em prática tais modelos. Esse discurso é o que se identifica com as formas de conceber as actividades a partir de fora, de conceber a resolução dos problemas a partir de entidades exteriores aos locais e não com os locais, que levam à não-participação dos interessados, que levam a que se criem situações de dependência, e é também o discurso de quem normalmente organiza a educação de adultos com base numa racionalidade técnica que leva a efeito acções muito dirigidas para o indivíduo, não integradas, acções dispersas, ou seja, sem uma definição estratégica coerente que é essencial para que se dê o desenvolvimento local, nomeadamente com a participação da educação de adultos.

Pensamos que, relacionado com o que foi dito, poderá estar o facto de grande parte das entidades não ter nenhum projecto educativo de adultos, uma filosofia de actuação que não se limite à realização de candidaturas a programas de forma mais ou menos avulsa. Na verdade, apenas em quatro entidades existem tais projectos.

A teoria diz-nos que o desenvolvimento local e as entidades que o praticam são espaços privilegiados de educação de adultos, espaços onde se combinam várias formas de educação de adultos. E efectivamente, pelos resultados obtidos, em muitas dessas instituições ela aparece em vários formatos e tem ocorrido duma forma regular. No entanto, o facto de essa actividade aparecer sem qualquer projecto que lhe dê consistência 
faz-nos interrogar a forma como a articulação entre educação de adultos e o desenvolvimento local se faz - ou não faz. Enfim, a questão é: afinal de contas, como aparece a educação de adultos no contexto do desenvolvimento local? E esta pode ser desdobrada noutras que podem ajudar a responder-lhe: como é que há entidades com uma actividade relevante em educação de adultos para a qual não têm um projecto definido? Como é que há entidades com estruturas próprias que não têm um projecto? Como é que há entidades com planos estruturantes da sua acção que desenvolvem essa actividade e ela não faz parte de tais planos? Afinal qual é a real importância dessa actividade nesse quadro do desenvolvimento local? Afinal qual é a estratégia definida para essa actividade?

Ao que parece, e tendo em conta o referido, haverá um certo desencontro na relação desenvolvimento local-educação de adultos. Quer dizer, esta existe, como já vimos, mas tendo em conta os dados recolhidos faz-nos pensar que existirá, em muitos casos, de forma avulsa, desligada da restante actividade das entidades, não fazendo parte dum todo cujo objectivo primordial deverá ser o desenvolvimento local. Parece podermos concluir estar perante a existência duma filosofia de actuação assente no curto prazo, que não irá muito para além da realização de candidaturas a programas que financiem tal actividade. Essa parece ser a política de actuação de muitas dessas instituições. A ser assim, será que tal actividade é vista por grande parte dessas entidades como uma fonte de financiamento? Será que o facto de ela estar entre suas principais actividades se reduz a isso? Se for assim, como pode ela contribuir para o desenvolvimento local?

No que toca ao processo/forma que a educação de adultos tem assumido nessas instituições (questão claramente relacionada com a anterior), considerámos duas dimensões: a existência duma educação de adultos realizada em articulação, ou não, com a restante actividade das instituições; e o tipo de participação dos destinatários das acções.

Na maior parte dos casos, a educação de adultos surge parcial ou residualmente integrada na restante actividade dessas instituições. De acordo com os en- trevistados, em 15 casos os destinatários dos projectos costumam intervir neles. Esses números por si só fariam concluir que os destinatários dos projectos têm papel activo em muitos casos. No entanto, uma leitura mais atenta, que nos remeta para as formas e fases em que essa intervenção ocorre, dá-nos outra perspectiva e faz-nos concluir precisamente o inverso, ou seja, a existência de uma participação ténue na maior parte dos casos e, em alguns, a ausência total de qualquer tipo de participação por parte dos destinatários dos projectos desenvolvidos, o que é completamente contraditório com as lógicas do desenvolvimento local e da educação de adultos.

\section{Dificuldades na implementação e execução da educação de adultos}

Terminamos dando conta das principais dificuldades identificadas pelos entrevistados quanto à implementação e execução da educação de adultos: rigidez e normas dos programas que enquadram os projectos, financeiras, formação paga aos formandos, dificuldade em seleccionar formandos, e desajuste entre um modelo de educação de adultos e a sua implementação no terreno.

A rigidez dos programas que enquadram e financiam os projectos e as respectivas acções materializa-se em vários efeitos negativos. Um dos efeitos referido foi a calendarização inadequada dos cursos de formação profissional, que é fixa: eles só se iniciam e terminam em datas previamente estabelecidas (início do ano ou a meio do ano). Ora, esse aspecto faz com que muita gente fique de fora das formações, por exemplo, porque não se vai para o desemprego apenas no início ou a meio do ano.

Outro efeito enunciado, fruto do forte condicionalismo das regras do Fundo Social Europeu (FSE), que se traduz numa uniformização e generalização cega, foi a não-realização dos projectos de acordo com aquilo que os técnicos gostariam e pensam que seria melhor fazer, tendo em conta a população com quem trabalham, admitindo alguns que o que se faz é uma adaptação dos destinatários e das ideias aos 
programas - e não o contrário. Esse condicionalismo tem como resultado a realização de actividades que podem não se adaptar à realidade. Haverá algo mais contraditório com as lógicas do desenvolvimento local do que essa prática? O desenvolvimento local tem de ser feito em todos os locais da mesma forma? Vejamos um extracto de um dos entrevistados que se referiram a esse aspecto:

Relativamente à formação profissional, está muito estandardizada. Temos que nos cingir, que nos orientar pelos regulamentos do FSE, está tudo predefinido e isso limita a formação que gostaríamos de dar a esse tipo de população. Continua tudo a ser muito rígido, não temos grande espaço de manobra [...] e depois o que acontece é que por vezes não se vai ao encontro daquilo que gostaríamos e ao que as pessoas gostariam [...]. Portanto, as regras são iguais para todos e em todo o lado e isso deixa pouco espaço de manobra para tentarmos adaptar à realidade e o que acontece é que temos que adaptar as pessoas aos programas e não o contrário...

Outro efeito negativo da uniformização desses programas, proveniente das normas existentes para seleccionar as pessoas, é a exclusão daqueles que já são mais excluídos. Na verdade, para poder aceder a tais acções tem-se que preencher, em alguns tipos de programas, alguns requisitos prévios, como estar inscrito nos Centros de Emprego e ter determinado nível de escolaridade, que afastam precisamente aquela franja da população que já se encontra afastada de muitas outras coisas, como ilustra o excerto de um dos entrevistados que se referiu a esse aspecto:

Um dos principais problemas é, sem dúvida, a pressão legislativa e os critérios impostos pela lei. Portanto, é querermos formar a comunidade e muitas vezes ser difícil encontrar um formando, ou porque não tem a $4^{\mathrm{a}}$ classe exigida, ou porque é um desempregado de longa duração mas não está inscrito no Centro de Emprego. Portanto, a situação face à lei das pessoas é muitas vezes impeditiva de trazer, se calhar, os mais necessitados à formação, e há muita gente que fica de fora. Porque aí também falha a informação das instituições públicas às comunidades, quer dizer, as pessoas das nossas aldeias não estão inscritas nos Centros de Emprego não é porque não queiram, é porque não sabem e ao não saberem estão automaticamente excluídas de cursos que lhes fazem falta...

Foi também dito que toda essa rigidez se traduz numa menor autonomia para realizar as actividades e sua planificação. Para além de todos esses efeitos, foi ainda referido que esse condicionalismo se traduz numa enorme dificuldade em gerir os projectos do ponto de vista administrativo, tendo sido relatado que uma parte significativa do tempo dos técnicos é gasto nessas actividades.

No geral, pode-se dizer que essa dificuldade se traduz em dois aspectos negativos: o risco da inadaptação da educação de adultos realizada aos locais e gentes a quem se destina; e a exclusão de muitas pessoas desses processos de educação - nomeadamente aquelas que são já as mais excluídas.

Outra das dificuldades mais apontadas foi a financeira. Esta traduz-se, essencialmente, na dificuldade em se cumprirem os pagamentos a serem feitos a formadores e formandos. O que, no entender dos entrevistados, se fica a dever à forma como se procedem aos financiamentos às instituições, que assenta na lógica dos reembolsos, ou seja, as entidades gestoras só libertam as verbas após prova de despesas efectuadas pelas instituições. Acontece que, de acordo com os entrevistados, ocorrem atrasos prolongados nesse processo de financiamento, o que dificulta ainda mais a tarefa das instituições e de quem nelas trabalha.

$\mathrm{O}$ facto de grande parte das actividades terem bolsas para os formandos foi apontado por um número significativo de técnicos como outra dificuldade. Isso porque, segundo eles, a motivação para a frequência de tais actividades passa a ser apenas o recebimento de tais bolsas, notando-se em muitos casos total desinteresse pela aprendizagem em si. Esse facto traduz-se, para além do alheamento de muitos relativamente à aprendizagem, como já dissemos, em problemas que têm a ver com o ter de se realizar os pagamentos a horas, sob pena de os cursos fecharem, ou ainda com 
problemas que surgem na altura da selecção dos formandos quando se procura contrariar a inclusão nos cursos de pessoas relativamente às quais foi detectada ser essa a única motivação para a sua frequência.

Um dos efeitos dessa forma de cativar pessoas para a formação é o prolongamento da dependência por parte de muitas delas, pois muitas andam de formação em formação, muitas vezes independentemente da área, não procurando rentabilizar aquilo que eventualmente aprenderam porque acabam, em muitos casos, por ganhar mais na formação do que num emprego que possam encontrar, ou que os técnicos lhes tenham encontrado, criando-se assim verdadeiros "profissionais da formação", pessoas que frequentam a formação sem outro objectivo que não seja o de receber as bolsas. Vejamos as palavras de um técnico relativamente a esse problema:

Há outra dificuldade, que é o facto de existirem bolsas para os formandos. Nós aqui, sempre que possível, tentamos pagar bolsas relativamente baixas, ao contrário do que acontece na maior parte das associações, que pagam o equivalente ao salário mínimo nacional. Isso compreende-se, pois é uma forma de captar mais gente. Nós só o fazemos em programas em que isso é obrigatório, como é o caso do Programa Inserção e Emprego. Mas evitamos, porque pensamos que não resolvemos nada dessa forma, só disfarçamos [...]. Mas isso é muito complicado, porque ninguém percebe muito bem como é que esteve numa formação a ganhar o salário mínimo sem realizar descontos e que depois foi trabalhar e acaba por receber menos do que na formação e portanto o que é bom é fazer formação e portanto eles vão de formação em formação. Ou seja, se puderem vão realizar formação toda a vida. Olhe aí é que é mesmo formação ao longo da vida...

A dificuldade em recrutar formandos foi também apontada por vários entrevistados. Pelos comentários realizados por alguns deles, percebe-se por que é que tal acontece, ou melhor, percebe-se parte do porquê, que aliás tem a ver com outros aspectos antes referidos. Estamos a referir-nos ao facto de conceberem-se os projectos com base na identificação de necessidades feita pelos técnicos sem a participação dos destinatários. Vejamos dois excertos que nos remetem para esse problema:

Um problema é que aquilo em que nós achamos ser necessário os adultos terem formação não ser reconhecido por eles como tal. É por isso que surge muitas vezes a questão da sua não-adesão, do seu não-envolvimento, e da sua não-motivação...

Outro problema é existir por vezes um desajuste entre aquilo que concebemos com base nas necessidades identificadas e depois o não conseguirmos adeptos suficientes para os cursos...

Conceber projectos para pessoas sem sua participação efectiva, realizar tal concepção sem saber afinal se, na verdade, os destinatários que se desenharam no projecto efectivamente existem, é algo que escapa a toda a lógica do desenvolvimento local e da própria educação de adultos. Não admira, por isso, que ocorram resistências, quer à adesão inicial às actividades, quer quando, estando nelas, os formandos não se envolvam, não se mostrem e estejam motivados. Até porque o que por vezes acontece é que, fruto dessa dificuldade em recrutar formandos, as instituições acabam por seleccionar pessoas para quem o projecto não foi pensado. $\mathrm{O}$ excerto seguinte é elucidativo quanto ao que acabámos de dizer:

Temos uma grande dificuldade no recrutamento de formandos e não somos só nós, isto é geral [...]. Portanto, temos esta grande dificuldade que depois impede muita coisa. Quer dizer, como nós nunca temos muitos candidatos aos cursos, temos pouca capacidade de selecção, porque se queremos 10 temos 12 e portanto só podemos eliminar 2. Mas muitas vezes temos a consciência de que não estamos a incluir na formação exactamente as pessoas que deveríamos estar a incluir e que se tivéssemos outra capacidade de selecção haveria um conjunto de pessoas que nunca eram seleccionadas, porque se vê logo que não têm o mínimo de motivação, nem as características esperadas [...]. Essa é, efectivamente, a maior dificuldade na altura de implemen- 
tar os cursos; quando temos que seleccionar 10,12 ou 15 pessoas é um bico-de-obra [...], fazem-se os cursos e depois as pessoas não aparecem...

Como vemos, há aqui uma série de aspectos que se encadeiam, produzindo um efeito de bola de neve que terá pouco a ver com aquilo que é preconizado pelas teorias do desenvolvimento local e da educação de adultos assentes na endogeneidade, nos saberes das pessoas.

Outra dificuldade referida e que nos parece significativa é a de não se conseguir pôr em prática certas partes dum modelo inovador de educação de adultos. Estamos a referir-nos ao modelo protagonizado pela ANEFA, mais precisamente a alguns instrumentos que tal agência pôs em prática para conseguir levar por diante sua filosofia de trabalho: os cursos EFA e os CRVCC. Efectivamente, parte dos entrevistados, embora tenham elogiado a filosofia materializada por esses dois instrumentos, levantavam algumas críticas quanto à forma como o processo estava a decorrer.

Relativamente aos cursos EFA, uma das críticas apontadas foi a dificuldade em conseguir trabalhar de forma articulada à componente da educação e à da formação, afirmando-se, por exemplo, que a parte profissional se encontra pouco trabalhada e completamente desfasada da realidade, ou seja, das necessidades do mercado de trabalho, e que se isso não for invertido se torna difícil manter as acções. Criticou-se também o facto de se estarem a introduzir com frequência transformações várias sobre algo que é de si novo, que estava a ser experimentado. Vejamos o que disse um dos entrevistados que criticou a forma como estavam a funcionar esses cursos:

Os cursos EFA estão muito bem estruturados na parte escolar; já não se pode dizer o mesmo da parte profissional, porque acho que aqui há algumas questões complicadas que a ANEFA vai ter que resolver a muito breve prazo porque senão vai ser muito complicado mantermos essas acções. Porque eu acho que a parte escolar está muito bem organizada, bem trabalhada ao nível dos referenciais etc. Mas, ao nível profissional, está muito pobre. Todo o trabalho que foi feito na parte escolar é preciso ser feito na parte profissional. Nesta utiliza-se a chapa 24, que já era usada pelo Instituto de Emprego. São os mesmos itinerários de qualificação, o sistema de avaliação também é idêntico. Portanto, essa parte deixa muito a desejar e é um problema grave, é uma questão complicada, e ou se dá o salto ou vai ser complicado manter isso. Quer dizer, tem que se fazer como fez na parte escolar [...], a parte profissional também tem que ser trabalhada por quem perceba dessas questões e em articulação com as empresas. Os perfis profissionais, e tudo isso, têm que ser aprofundados e alterados, os itinerários de qualificação não estão adequados, não foram feitos em articulação com as empresas, não se ajustam ao mercado de trabalho. Quer dizer, depois vamos com os formandos de padaria para uma padaria e lá dizem-nos que eles não precisam nada de saber fazer aquilo que andaram a aprender, mas sim outras coisas. Portanto, isso é um problema grave, esses itinerários têm que ser trabalhados doutra forma e com os empresários, com as pessoas que trabalham nessas áreas para se perceber o que realmente é preciso, enfim para se estabelecerem referenciais de competências para as várias profissões. E isso acho que é um trabalho que cabe à ANEFA, porque ela não se pode esquecer que tem tanto a parte escolar como a parte profissional no seu modelo, conforme consta na portaria que a regula, mas se não houver esse esforço é difícil trabalhar as duas áreas de forma articulada...

As críticas realizadas aos CRVCC foram também no sentido da existência dum desfasamento entre as medidas pensadas em termos desse modelo e a capacidade para as pôr em prática. Mais concretamente, a crítica realizada recaiu sobre a imensa dificuldade de concretizar uma das funções previstas no âmbito desse instrumento: o encaminhamento de adultos para outras respostas quando eles não encontram resposta dentro do centro, sendo aconselhada pela ANEFA a procura preferencial de resposta no interior da própria ANEFA (cursos EFA). E o problema começa aqui, ou seja, na tal procura de respostas, quer dentro quer fora da agência. É que, segundo os entrevistados, elas praticamente não existem, sobretudo quando se trata de adultos que se encontram a trabalhar, ou se existem não se sabe que existem. Essa dificuldade resulta também, 
para além da escassez de respostas alternativas, quer internas, quer externas, da falta de articulação entre as diversas instituições ligadas à educação de adultos. Assim, parece estarmos perante um caso de concepção de um modelo que em si é bom, mas que não terá sido realizado de modo integrado, de modo concertado e articulado, quer interna, quer externamente.

Esse aspecto é preocupante. Não adiantará de muito ter modelos inovadores, assentes em princípios correctos, quando não se agilizaram mecanismos para os pôr em prática.

Essas foram algumas das dificuldades apontadas pelos entrevistados, dificuldades que nos ajudam a perceber melhor a forma como a educação de adultos é construída e praticada nesse contexto do desenvolvimento local.

\section{Uma reflexão final}

O estudo que efectuámos leva-nos a dois tipos de considerações distintas. Por um lado, a educação de adultos é uma realidade inegável em várias das ONGDLs do norte de Portugal. Efectivamente, algumas delas têm forte envolvimento em actividades desse género.

Por outro lado, considerando o que fomos referindo, a educação de adultos praticada nessas instituições pouco terá a ver com os princípios orientadores do desenvolvimento local e da própria educação de adultos ligada a ele. Esse risco é tanto maior quanto maior for a dependência financeira das instituições e dos técnicos que nelas trabalham. Nesses casos, mais probabilidades existem, ou maior será a tendência para se fazer um uso mecânico de determinados sistemas especializados de conhecimento que vão ao encontro dos modelos teóricos e políticos que estejam na base dos programas a que concorrem, para assim poderem aceder a tais financiamentos, e com isso maiores poderão ser as probabilidades de os projectos assim aprovados não corresponderem aos reais problemas locais, não responderem às necessidades efectivamente sentidas pelas comunidades, aparecendo, dessa forma, desfasados da realidade.
Uma das questões que se põem é se aqueles que em nível local concebem essa educação de adultos pensam nisso como um problema, se reflectem sobre isso e de que forma o fazem. Já vimos que alguns, para não dizer todos, têm perfeita consciência de que as práticas que executam, ou parte delas, têm muito pouco a ver com os princípios que enquadram a educação de adultos no desenvolvimento local; alguns inclusive realizam crítica sobre isso, mas muitos deles não incorporam na sua acção esse discurso mais crítico, pelo que, em termos dos contextos onde actuam, tal discurso não produzirá nenhum efeito.

\section{Referências bibliográficas}

ALLEGRINI, Maria. La educación para el desarrollo local: una estrategia para la participación social. Pamplona: Eunsa, 2000.

ANIMAR - Associação Portuguesa para o Desenvolvimento Local. Guia das Iniciativas de Desenvolvimento Local. Messejana: ANIMAR, 1998.

BRÁS, José. Novos objectivos, métodos e instrumentos: um futuro para as ADLs. In: ALBINO, José (Org.). Desenvolver (des)envolvendo: reflexões e pistas para o desenvolvimento local. Messejana: Esdime, 2001. p. 65-87.

CANÁRIO, Rui. Educação de adulto: um campo e uma problemática. Lisboa: Educa, 1999.

CANDEIAS, José. A propósito das associações de desenvolvimento local do Alentejo. Alcáçovas: ATD, 2002.

CRISTÓVÃO, Artur. Das (des)articulações formação-investigaçãoextensão. Economia e Sociologia, n. 69, p. 149-164, jan./jun. 2000 .

DUBAR, Claude; GADÉA, Charles. Sociologia da formação pósescolar. In: CARRÉ, Phillipe; CASPAR, Pierre (Dir.). Tratado das ciências e das técnicas da formação. Lisboa: Instituto Piaget, 2001. p. 143-160.

ERASMIE, Thord. Apresentação. In: LIMA, Licínio (Org.). O projecto - Viana (1983-1988). Braga: Universidade do Minho, 1990. p. 13-17.

FERRANDO, Maria. Educación de personas adultas y desarrollo rural. Córdoba: Universidad de Córdoba, 1996.

FREIRE, Paulo. Extensão ou comunicação?. Rio de Janeiro: Paz e Terra, 1971.

. A pedagogia do oprimido. Porto: Afrontamento, 1975. 
As organizações não-governamentais de desenvolvimento local e sua prática educativa de adultos

Educação política e conscientização. Lisboa: Sá da

Costa, 1977

FRIEDMAN, John. Empowerment: uma política de desenvolvimento alternativo. Oeiras: Celta, 1996.

GUIMARÃES, Paula; SANCHO, Amélia. A participação nas associações: novos desafios à educação de adultos. In: SIMÕES, António et al. (Orgs.). Modelos e práticas em educação de adultos. Coimbra: Napfa, 2001. p. 159-175.

GUSMÃO, Maria; MARQUES, António. Conferências Internacionais da UNESCO sobre educação de adultos: Elsinore (1949), Montreal (1960), Tóquio (1972). Braga: Universidade do Minho, 1978.

HINOJAL, Isidoro. Agencias y agentes de la educación de adultos. In: ORTEGA CARRILLO, José Antonio (Coord.). La educación de adultos: situación actual y perspectivas de futuro. Granada: Fundación Educación y Futuro, 1995. p. 221-243.

JARVIS, Peter. Content, purpose and practice. In: TITMUS, Colin (Ed.). Lifelong education for adults: an international handbook. Oxford: Pergamon Press, 1989. p. 22-28.

. Adult and continuing education: theory and practice. London: Routledge, 1995.

; CHADWICK, Alan (Eds.). Training adult educators

in Western Europe. London: Routledge, 1991.

JOVER, Daniel. La formación ocupacional. Madrid: Editorial Popular, 1999.

KNOX, Alan. Strengthening adult and continuing education. San Francisco: Jossey-Bass, 1993.

LIMA, Licínio. Associações para o desenvolvimento no Alto Minho. Viana do Castelo: Centro Cultural do Alto Minho, 1986.

Fórum de educação de adultos (1987-1993). In:

LIMA, Licínio (Org.). Educação de adultos: fórum I. Braga: Universidade do Minho, 1994. p. 13-26.

LOUREIRO, Armando. O trabalho, o conhecimento, os saberes $e$ as aprendizagens dos técnicos de educação de adultos numa $O N G D L$ : contribuições etnográficas para uma renovação da sociologia da educação. Tese (Doutorado em Sociologia da Educação) - Departamento de Educação e Psicologia, Universidade de Trás-os-Montes e Alto Douro, 2006.

LOVETT, Tom. Adult education, community development and working class. Nottingham: DAE/University of Nottingham, 1982.

MELO, Alberto. Desenvolvimento local como processo educativo. REDE, n. 2, p. 58-63, nov. 1988.
. Educação e formação para o desenvolvimento rural. In: LIMA, Licínio (Org.). Educação de adultos: fórum I. Braga: Universidade do Minho, 1994. p. 137-149.

MERRIAM, Sharan; BROCKETT, Ralph. The profission and practice of adult education. San Francisco: Jossey-Bass, 1997.

MONTEIRO, Alcides. Associativismo e novos laços sociais. Tese (Doutorado em Sociologia) - Departamento de Sociologia, Universidade da Beira Interior, 2002.

MOSELE, Malcolm; CASPAR, René. Inovar pela formação, inovar na formação: a formação ao serviço do desenvolvimento territorial. Bruxelas: Observatório Europeu Leader, 2000.

MUGE, Amélia. Criativo ou criação: o inevitável dilema do sentido da formação. REDE, n. 2, p. 64-75, nov. 1988.

NORBECK, Johan. Associações populares para o desenvolvimento. Lisboa: Ministério da Educação, 1983.

PALMA, Fernando; FLECHA, Ramón. Educación de personas adultas. In: PETRUS, Antonio (Coord.). Pedagogía social. Barcelona: Ariel, 1998. p. 154-177.

PEDROSO, Paulo. Formação e desenvolvimento rural. Oeiras: Celta, 1998.

QUINTANA, José (Coord.). Investigación participativa. Madrid: Narcea, 1986.

Pedagogía comunitaria: perspectivas mundiales de educación de adultos. Madrid: Narcea, 1991.

. Experiencias en educación de adultos. In: ORTEGA CARRILlO, José Antonio (Coord.). La educación de adultos: situación actual y perspectivas de futuro. Granada: Fundación Educación y Futuro, 1995. p. 191-198.

RAMOS, Emilio. Alfabetización, desarrollo y cambio. In: RAMOS, Emilio (Ed.). Espacios para el desarrollo local. Barcelona: PPU, 2001. p. 63-80.

ROGERS, Alan. La educación de adultos para el desarrollo. Madrid: Universidad Popular, 1995.

ROMANS, Mercè; VILADOT, Guillem. La educación de personas adultas: cómo optimizar la prática diaria. Barcelona: Paidós, 1998. ROTHES, Luís. Os projectos de desenvolvimento local como contextos de excelência da educação de adultos: realidade e desafios. REDE, edição especial, p. 46-47, nov. 1998.

SÁEZ, Juan; PALAZÓN, Francisco (Coords.). La educación de adultos: una nueva profesión? Valencia: Nau Llibres, 1994.

SARRAMONA, Jaume. La alfabetización. In: SARRAMONA, Jaume et al. Educación no formal. Ariel: Barcelona, 1998. p. 2944. 
SEITTER, Wolfgang. Educación de adultos y sistema educativo: un enfoque comparativo. In: ORTEGA CARRILLO, José Antonio (Coord.). La educación de adultos: situación actual y perspectivas de futuro. Granada: Fundación Educación y Futuro, 1995. p. $57-87$.

SILVA, Augusto. Educação de adultos, educação para o desenvolvimento. Porto: ASA, 1990.

SOARES, Maria. Formação para o desenvolvimento: formação/ inserção profissional territorializada. Faro: In Loco, 2001.

UNESCO - Organização das Nações Unidas para a Educação, a Ciência e a Cultura. Recomendação da UNESCO sobre a educação de adultos: aprovada na $19^{\mathrm{a}}$ sessão da Conferência Geral de Nairóbi, 26 de novembro de 1976. Lisboa: Direcção Geral da Educação de Adultos, 1976.

. A study on strategies for rural development and the role of education. Paris: UNESCO, 1982.

. Quartième conferénce internationale sur l'éducation des adultes: rapport final. Paris: UNESCO, 1985.

$V$ Conferência Internacional sobre Educação de

Adultos: declaração final e agenda para o futuro. Lisboa: Ministério da Educação, 1998.

WERTHEIN, Jorge. Educación de adultos en los procesos de desarrollo rural. Santiago do Chile: OREALC, 1983.
ARMANDO PAULO FERREIRA LOUREIRO, doutor em sociologia da educação pela Universidade de Trás-os-Montes e Alto Douro (Portugal), é professor auxiliar no Departamento de Educação e Psicologia da Universidade de Trás-os-Montes e Alto Douro. É membro do Instituto Paulo Freire de Portugal, do Centro de Investigação e Intervenção Educativas da Universidade do Porto e do Centro de Estudos Transdisciplinares para o Desenvolvimento da Universidade de Trás-os-Montes e Alto Douro. Publicações recentes: "A universidade ao encontro da comunidade: traços do perfil da actividade de extensão de uma universidade", em co-autoria comArtur Cristóvão (Revista Portuguesa de Educação, v. 13, n. 2, p. 243-266, jul./dez. 2000); "O trabalho e o saber dos profissionais-técnicos de educação e formação de adultos em contexto associativo" (In: CARIA, Telmo (Org.). Saber profissional. Coimbra: Almedina, 2005. p. 169-195); e "O trabalho e o uso do conhecimento em técnicos de educação de adultos" (In: VIEIRA, J. (Ed.). A socioloxía e os novos retos. Corunha: Universidade da Coruña/Faculdade de Socioloxía, 2007. p. 2-22). Projecto de investigação actual: "Estudo sobre a elaboração participada de planos directores de formação - Baixo Tâmega”.E-mail: aloureiro@utad.pt

Recebido em novembro de 2007 Aprovado em fevereiro de 2008 
Armando Loureiro

\section{As organizações não-governamentais de desenvolvimento local e a sua prática educativa de adultos: uma análise no norte de Portugal}

Este artigo dá conta de uma investigação realizada junto a organizações não-governamentais de desenvolvimento local com actividades de educação de adultos, no norte de Portugal. Nele problematiza-se a relação teórica que vê a educação de adultos como factor de desenvolvimento local. Os dados mostram que, no caso investigado, apesar de tais organizações realizarem acções de educação de adultos variadas e frequentes, a forma como elas estão a ser postas em prática comprometerá a relação causal antes enunciada.

Palavras-chave: educação de adultos; desenvolvimento local; organizações não-governamentais

\section{Non-governmental local development organizations and their educative practice with adults: an analysis of their activities in the north of \\ Portugal \\ This article is based on an investigation carried out among non-governmental local development organizations devoted to adult education in the north of Portugal. In $i$, we question the theoretical relation}

which considers adult education as a factor of local development. The data show that in the case under study, although these organizations carry out varied and frequent activities of adult education, the way in which they are put into practice will compromise the previously enunciated causal relationship.

Key words: adult education; local development; non-governmental organizations

Las organizaciones no gubernamentales de desarrollo local y su práctica educativa de adultos: un análisis en el norte de Portugal

Este artículo trata de una investigación realizada junto a organizaciones no gubernamentales de desarrollo local con actividades de educación de adultos, en el norte de Portugal. En él se trata el problema de la relación teórica que ve la educación de adultos como un factor de desarrollo local.

Los datos muestran que, en el caso investigado, a pesar de que tales organizaciones realicen acciones de educación de adultos variadas y frecuentes, la forma como ellas están siendo puestas en práctica comprometerá la relación causal antes enunciada.

Palabras clave: educación de adultos; desarrollo local; organizaciones no gubernamentales 